\title{
ZnO Nanowire-supported Ag Catalyst for Methanol Steam Reforming
}

\author{
J. X. Liu ${ }^{1,2}$, J. Xu ${ }^{3}$, Y. D. Huang ${ }^{2}$ and J. Y. Liu ${ }^{1}$ \\ 1. Department of Physics, Arizona State University, Tempe, Arizona 85287, USA \\ 2. College of Chemical Engineering and Technology, Harbin Institute of Technology, Harbin 150001, \\ China \\ 3. School for Engineering of Matter, Transport and Energy, Arizona State University, Tempe, Arizona \\ 85287, USA
}

\begin{abstract}
Alternative energy sources, such as various fuel cell technologies, have attracted intense attention due to their high efficiency and low emissions of pollutants. Methanol, with its high hydrogen/carbon ratio, low sulfur content and the absence of carbon-carbon bonds, has been identified as a highly suitable source for onboard production of hydrogen [1]. Among several reactions for converting methanol to $\mathrm{H}_{2}$, methanol steam reforming (MSR) is one of the most attractive processes because it can provide a high $\mathrm{H}_{2}$ content and an extremely low level of $\mathrm{CO}$ in the product [2]. We report here our recent study of $\mathrm{Ag}$ nanoparticles (NPS) supported on ZnO nanowires (NWs) as a catalyst for MSR reaction.
\end{abstract}

$\mathrm{ZnO} \mathrm{NWs}$ were fabricated by a thermal evaporation-condensation method in a high-temperature tube furnace. The $\mathrm{Ag} / \mathrm{ZnO}$ nanocatalysts were prepared by a deposition-precipitation method. ZnO NWs were dispersed into deionized water and the suspension was under constant stirring. Then $\mathrm{AgNO}_{3}$ aqueous solution was added stepwise to the suspension, during which the $\mathrm{pH}$ value of the mixture was maintained at a fixed value by adding appropriate amounts of $\mathrm{NaOH}$ solution. After filtration and being washed with deionized water, the resultant solid was dried at $60{ }^{\circ} \mathrm{C}$ overnight and calcined at $400{ }^{\circ} \mathrm{C}$ for 4 hours. The catalyst was reduced by hydrogen at $400{ }^{\circ} \mathrm{C}$ for 2 hours, prior to MSR reaction which was conducted in a fixed-bed plug-flow reactor. A mixture of 1.5: 1 moles of water-methanol was pumped using a syringe pump at $0.6 \mathrm{ml} \mathrm{h}^{-1}$. The reaction feed was preheated to $160{ }^{\circ} \mathrm{C}$ to vaporize the methanol/water mixture. The JEOL JEM-ARM200F aberration-corrected scanning transmission electron microscope (STEM), with a nominal image resolution of $0.08 \mathrm{~nm}$ in the high-angle annular dark-field (HAADF) imaging mode, was used to investigate the structure of the synthesized $\mathrm{Ag} / \mathrm{ZnO}$ catalysts.

Figure 1a shows a backscattered SEM image of the synthesized $5 \mathrm{wt} \% \mathrm{Ag} / \mathrm{ZnO} \mathrm{NW}$ catalyst, revealing the general morphology of the $\mathrm{ZnO}$ NWs and the presence of some large Ag NPs. Figure 1b displays a low magnification HAADF image of a representative $\mathrm{Ag} / \mathrm{ZnO} \mathrm{NW}$, revealing small clusters of $\mathrm{Ag}$ on the $\mathrm{ZnO} \mathrm{NW}$. It is interesting to note that some etch pits (dark patches), often associated with the small Ag clusters, can be clearly seen on the surfaces of the $\mathrm{ZnO} N W$. At high magnifications individual Ag single atoms, located on the positions of the Zn columns, can be clearly observed (indicated by the arrows in Fig. 1c). The stability of these Ag atoms under electron beam irradiation suggests that they may be embedded onto the $\mathrm{ZnO}$ surfaces, replacing $\mathrm{Zn}$ cations. The performance of the $\mathrm{Ag} / \mathrm{ZnO} \mathrm{NW}$ catalyst was evaluated at different temperatures (Fig. 1d). Pure ZnO NWs, also a catalyst for the MSR reaction, was tested as a control. It should be noted that the $\mathrm{Ag} / \mathrm{ZnO} \mathrm{NW}$ catalyst has a much higher activity and better selectivity toward $\mathrm{CO}_{2}$ than the pure $\mathrm{ZnO}$ NWs. Optimization of the catalyst synthesis processes and applications to other types of catalytic reactions will be discussed [3]. 


\section{References:}

[1] L. F. Brown, Int. J. Hydrogen Energy 26 (2001), p. 381.

[2] A. Haryanto et al., Energy \& Fuels 19 (2005), p. 2098.

[3] This research was funded by Arizona State University. We gratefully acknowledge the use of facilities within the LeRoy Eyring Center for Solid State Science at Arizona State University.
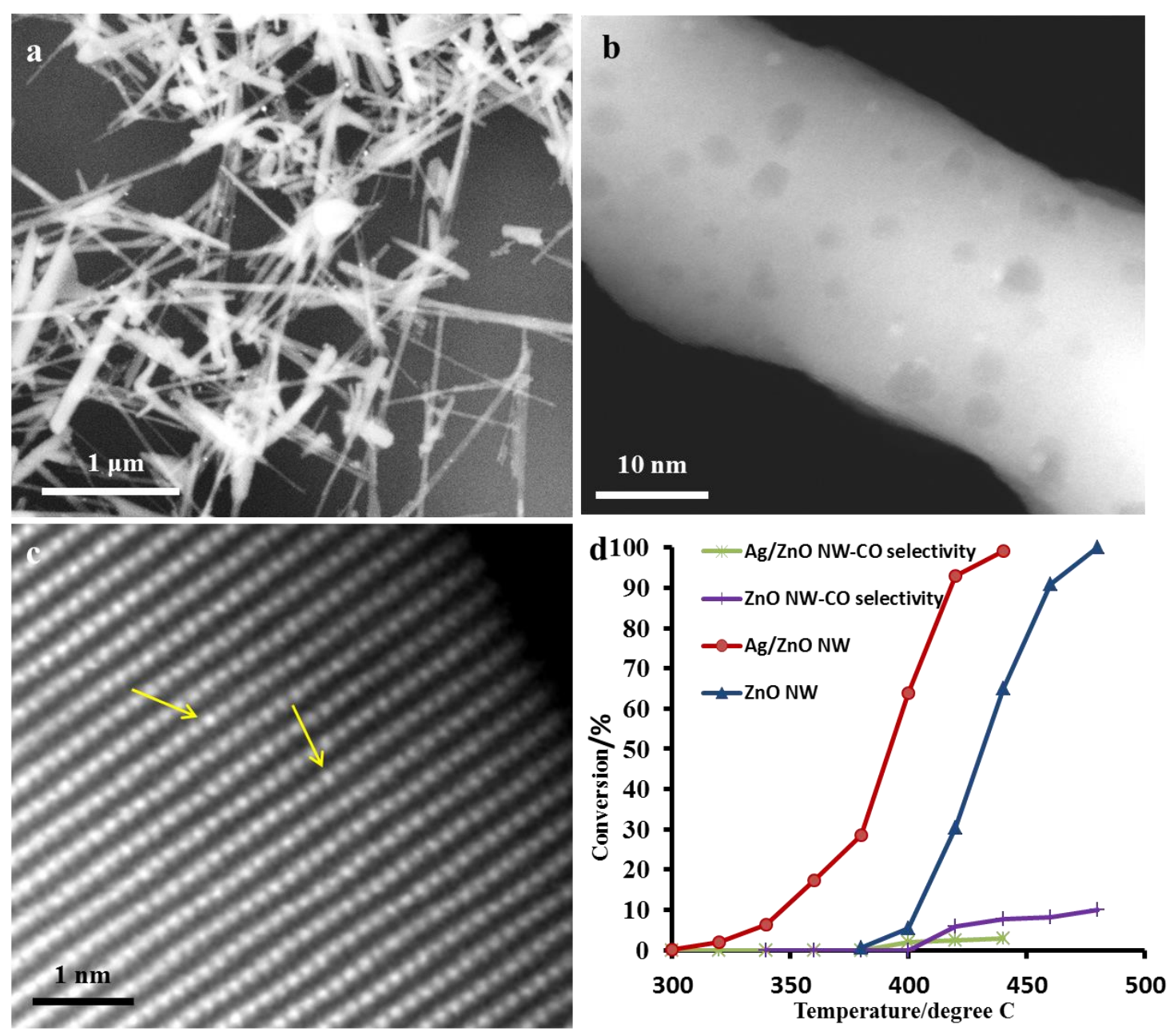

Figure 1. Backscattered SEM image of an $\mathrm{Ag} / \mathrm{ZnO} \mathrm{NW}$ catalyst shows some large Ag NPs (a). Aberration-corrected HAADF images of a $\mathrm{Ag} / \mathrm{ZnO} \mathrm{NW}(\mathrm{b}, \mathrm{c})$, revealing small Ag clusters, etch pits on the $\mathrm{ZnO} \mathrm{NW}$ surfaces and isolated individual $\mathrm{Ag}$ atoms on the positions of the $\mathrm{Zn}$ columns of the $\mathrm{ZnO}$ NW. The ZnO NW in Fig. 1c was oriented close to the ZnO [10-10] zone axis. Methanol conversion as a function of reaction temperature on the $\mathrm{Ag} / \mathrm{ZnO}-\mathrm{NW}$ catalyst for MSR reaction (methanol/water (mole ratio): $1 / 1.5\left(0.6 \mathrm{ml} / \mathrm{h}\right.$ in liquid), gas hourly space velocity of $\sim 54,000 \mathrm{ml} \mathrm{g}^{-1}$ cat $\mathrm{h}^{-1}$ ). The $\mathrm{ZnO} \mathrm{NWs} \mathrm{were}$ tested as a control. 